\title{
Efficacy of Post Operative Analgesia with Epidural Tramadol, Fentanyl And Buprenorphine
}

\author{
${ }^{1}$ L.Giridhar Naik, ${ }^{2 *}$ B.Venkateswar Rao ${ }^{3}$ R. Pandu Naik . \\ ${ }_{1,2}$ Assistant Professor, ${ }^{3}$ Professor, Department of Anesthesiology, Osmania General Hospital and Osmania \\ Medical College, Hyderabad, Telangana.
}

\begin{abstract}
Aim : To compare postoperative analgesia among epidural Tramadol, Fentanyl \& Buprenorphine over first 24 hours in terms of onset of analgesia, duration, quality of analgesia, number of doses, haemodynamic parameters, respiratory rate and side effects.

Methods And Materials: This study was a prospective comparative randomized study. After ethical committee approval a total of 60 patients undergoing elective lower limb or lower abdominal surgeries : were divided into three groups (Group T, Group F and Group B) of twenty each. All the patients were premedicated with Tab. Alprazolam $0.25 \mathrm{mg}$ at 10pm night before surgery and Tab.Ranitidine $150 \mathrm{mg}$ at 7 am on day of surgery. Results. The demographic profile (age wise and weight wise distribution) was comparable in all the three groups. The onset of analgesia was shortest $(3.75 \pm 0.36 \mathrm{~min})$ in fentanyl group followed by tramadol $(7.76 \pm$ $0.65 \mathrm{~min})$ and buprenorphine $(13.98 \pm 1.46 \mathrm{~min})$ groups which is statistically significant. The duration of analgesia was $232.25 \pm 19.15$ min in fentanyl group, $434.75 \pm 33.61$ min in tramadol group and $1094 \pm 27.29$ min in buprenorphine group which is statistically significant. The number of doses required in fentanyl group are $6.7 \pm 0.7$, tramadol group are $4.0 \pm 0.0$ and buprenorphine group are $2.0 \pm 0.0$. The quality of analgesia which was assessed using VAS score showed that the score was less than 1 in all the groups during 24hrs of study period. The changes in systolic blood pressures recorded at $0,1,2,3,4,5,8,9,10,11,12,18$ and 24 hrs among the three groups were statistically not significant. The increase observed at 6 and 7 hrs in tramadol and fentanyl groups compared with buprenorphine group was statistically significant which can be explained based on shorter duration of action of tramadol and fentanyl leading to wearing of the analgesic effect. Respiratory rate showed no significant changes at $0,1,2,3,4,5,8,9,10,11,12,18$ and 24 hrs among the three groups statistically. The decrease in respiratory rate in buprenorphine group compared to tramadol and fentanyl groups was statistically significant at 6 and 7 hrs.

Conclusion: With advent of newer opioids with fewer side effects, the search for appropriate opioid for epidural administration to provide postoperative pain relief still continues. With the introduction of infusion pump in postoperative ward further research can be directed towards patient controlled analgesia and continuous epidural analgesia.
\end{abstract}

\section{Introduction}

Pain is more terrible lord of mankind than death itself ${ }^{1}$. The taxonomy committee of International Association for the study of pain defines pain as "An unpleasant sensory and emotional experience associated with actual or potential tissue damage or described in terms of such damage" ${ }^{2}$. Pain being a subjective phenomenon is perceived only by the sufferer ${ }^{2}$. In no symptom are the patients more inconsistent and unreliable as they are while describing the pain ${ }^{2}$. Operative pain is a self limiting process which is most severe after surgery and thereafter gradually diminishes over next 24 hours ${ }^{1}$. Post-operative pain is considered a form of acute pain due to surgical trauma with an inflammatory reaction and initiation of an afferent neuronal barrage ${ }^{2}$. It is a combined constellation of several unpleasant sensory, emotional and mental experiences precipitated by the surgical trauma and associated with autonomic, endocrine-metabolic, physiological and behavioral responses ${ }^{2}$. Despite the advances in the knowledge of mechanism of the pathophysiology of pain, the pharmacology of analgesics and the development of more effective techniques, patients continue to experience considerable pain after surgery ${ }^{3}$. Post operative pain has drawn the attention of a large number of workers as it is one of the most distressing outcomes of any surgery, and its ablation brings a great relief to the suffering patient ${ }^{4}$. Traditionally opioids and NSAIDs have been given by various means to provide an effective post operative analgesia however all of these have their limitations and drawbacks ${ }^{4}$. Epidural analgesia is a safe technique for post operative pain relief and equivalent to traditional analgesic methods ${ }^{5}$. Epidural analgesia is considered by many to be the gold standard analgesic technique for major surgery ${ }^{6}$. Patients can be mobilized and resume normal activities more quickly with epidural analgesia compared to parenteral opioids ${ }^{6}$. Known benefits of post operative epidural analgesia are superior analgesia, improved pulmonary function, fewer cardiac ischemic events, shorter recuperation after joint surgery, better graft survival after lower limb vascular 
procedures, increased bowel mobility, associated with an early aggressive mobilization ${ }^{7}$. One of the most exciting developments in modern medicine is the knowledge of specific opiate receptors in substantia gelatinosa of Rolando of the posterior horn ${ }^{8}$. This has resulted in wide spread use of epidural opiates in the treatment of pain $^{8}$. They have the advantage of providing maximal analgesia with minimal dosage, thereby reducing the associated complications ${ }^{4}$. Also they can be given repeatedly / continually through the indwelling epidural catheter, thus providing prolonged analgesia in post operative period ${ }^{4}$. It has been proposed that opiates act locally and once deposited in epidural space diffuse through dura and bind to their specific receptors ${ }^{8}$. The more lipophilic the substance the greater will be its penetration through dura ${ }^{8}$. The opiates with greater affinity for the receptor sites will produce longer duration of analgesia ${ }^{6}$. Epidural morphine (preservative free form) has been extensively used for post operative analgesia ${ }^{8}$. It is one of preferred opiates because of its long duration of action with low dosage ${ }^{8}$. However, many side effects such as nausea, vomiting, pruritis, urinary retension and delayed respiratory depression have been reported ${ }^{8}$. Tramadol is a weak opioid agonist analgesic with a typical clinical profile ${ }^{9}$. It interacts with opioid receptors mu, alpha and delta ${ }^{9}$. At doses equipotent with pethidine, typical opioid side effects are less pronounced with Tramadol ${ }^{9}$. The absence of clinically relevant respiratory depression following epidural Tramadol compared with epidural morphine is attributable to different mechanisms of their analgesic action? ${ }^{9}$. It can be used to provide prolonged post operative analgesia without serious side effects ${ }^{9}$. Fentanyl, a $\mu$-opiate receptor agonist which is highly lipophylic, has analgesic potency greater than morphine ${ }^{5}$. The respiratory depressant effect of Fentanyl is less pronounced and of shorter duration as compared to morphine and pethedine ${ }^{5}$. The new opioid Buprenorphine is a thebaine derivative, semisynthetic having both agonist as well as antagonist properties ${ }^{8}$. It is highly lipid soluble and has higher affinity for opioid receptor, so the chances of side effects and addiction will be minimal and can safely be used epidurally ${ }^{8}$. The present study was conducted to compare the efficacy of post operative analgesia with epidural Tramadol, Fentanyl and Buprenorphine.

\section{Materials And Methods}

The present clinical study was conducted during the period of October 2007 to September 2009. This study was a prospective comparative randomized study. After ethical committee approval a total of 60 patients undergoing elective lower limb or lower abdominal surgeries were included in the study.

Inclusion criteria were ASA I and II, age between 18-45 years, both males and female patients.

Exclusion criteria was ASA physical status III and above, pregnancy, uncontrolled hypertensive patients, surgeries involving bladder, patients refusal to anaesthetic technique and contra-indications to regional anaesthesia.

All the patients were thoroughly examined clinically during the preanaesthetic evaluation and the routine laboratory investigations were done. They were explained about the study and the anaesthetic technique. A valid, written and informed consent was obtained for the same. All the patients were kept nil by mouth from $10 \mathrm{pm}$ day prior to surgery and premedicated with tab.Alprazolam $0.25 \mathrm{mg}$ at $10 \mathrm{pm}$ night prior to surgery and tab.Ranitidine $150 \mathrm{mg}$ at $7 \mathrm{am}$ on the day of surgery with sips of water. Sixty patients were randomly allocated into three groups using computer generated random numbers by simple randomization technique. 60 sealed envelops with the treatment allotment arranged in random order were used. As and when a patient was taken into study one envelop was opened in the serial order from the prearranged pack of envelops. Envelop was opened just before start of surgery. The patients as well as investigator recording the effect were not aware of which drug was being administered to a particular patient. Thus double blinding technique was ensured to eliminate bias. The patients were divided into three groups as follows; Group T: Tramadol group $(n=20)$, Group F: Fentanyl group $(n=20)$, Group B: Buprenorphine group $(n=20)$. In the preoperative room, all the patients were reassessed on the day of surgery. Intravenous line was secured with $18 \mathrm{G}$ IV cannula and ringer lactate solution was started. For every patient, a combined spinal epidural procedure was performed under all aseptic precautions. With the patient in sitting position, $18 \mathrm{G}$ epidural touhy needle was introduced in $\mathrm{L}_{2}-\mathrm{L}_{3}$ interspinous space. The epidural space was identified with a loss of resistance technique and an $18 \mathrm{G}$ epidural catheter was threaded in the space. $3 \mathrm{ml}$ of $2 \%$ Xylocaine with adrenaline (1:200000) was given as a test dose to rule out intrathecal or intravascular placement of epidural catheter. Sub arachnoid block was performed in $\mathrm{L}_{3}-$ $\mathrm{L}_{4}$ space using $25 \mathrm{G}$ spinal needle with $15 \mathrm{mg}$ of inj.Bupivicaine $0.5 \%$ heavy. No analgesics were administered during the intraoperative period and patient was shifted to postoperative ward after completion of surgery. In the postoperative ward, when patient complained of pain, haemodynamic parameters - pulse rate, systolic blood pressure, diastolic blood pressure, mean arterial pressure, respiratory rate and VAS score were noted (0hrs). Then Group T patients received epidural top ups of inj.tramadol $1 \mathrm{mg} / \mathrm{kg}$ diluted to $10 \mathrm{ml}$ with distilled water whenever they had pain for $24 \mathrm{hrs}$ from the first dose. Group F patients received epidural top ups of inj.fentanyl $1 \mu \mathrm{g} / \mathrm{kg}$ diluted to $10 \mathrm{ml}$ with distilled water whenever they had pain for $24 \mathrm{hrs}$ from the first dose. Group B patients received epidural top ups of inj.buprenorphine $3 \mu \mathrm{g} / \mathrm{kg}$ diluted to $10 \mathrm{ml}$ with distilled water whenever they had pain for $24 \mathrm{hrs}$ from the first dose. In all the patients intensity of pain and pain relief following injection 
of the drug in epidural space was assessed by Visual Analogue Scale (VAS) (0 - no pain to 10 - worst imaginable pain). Onset of analgesia, duration of analgesia and frequency of requirement of top ups were also noted.

Figure 1: Visual Analogue Scale

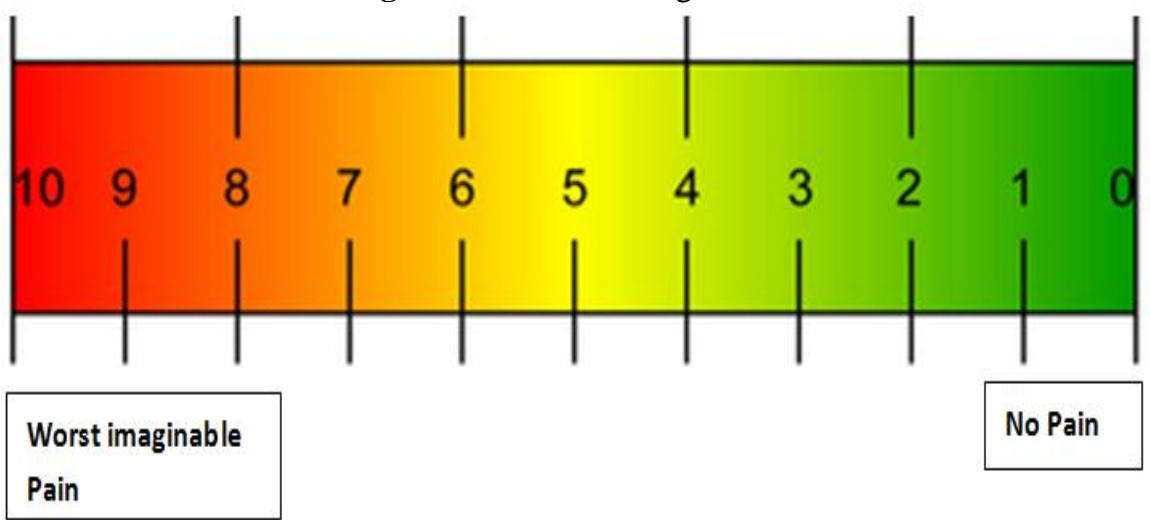

Pulse rate, systolic blood pressure, diastolic blood pressure, mean arterial pressure, respiratory rate and VAS score were recorded hourly from first dose for first 12 hours and $6^{\text {th }}$ hourly for next 12 hours. Side effects if any were also noted. All the data was presented in a tabular form, analysed and compared using analysis of varience (ANOVA) for repeated measures to detect differences with in the groups and post-hoc analysis with LSD for multiple comparisions between the groups for changes in all the parameters. $\mathrm{P}$ - value of less than 0.05 was considered significant. The obtained results were compared with those of the existing studies to arrive at a conclusion.

\section{Results}

Table 1 Demographic distribution, onset of analgesia and duration of analgesia in study.

\begin{tabular}{|c|c|c|c|c|c|c|}
\hline \multirow{2}{*}{$\begin{array}{c}\text { Age } \\
\text { (in years) }\end{array}$} & Group T & Group F & Group B & GpT-GpF & GpT-GpB & GpB-GpF \\
\cline { 2 - 7 } & $34.60 \pm 8.89$ & $33.15 \pm 8.62$ & $36.15 \pm 8.61$ & 0.600 & 0.576 & 0.280 \\
\hline Weight(Kgs) & $55.5 \pm 6.57$ & $59.6 \pm 6.51$ & $57.4 \pm 6.37$ & 0.050 & 0.368 & 0.288 \\
\hline $\begin{array}{c}\text { Onset of } \\
\text { analgesia(mins) }\end{array}$ & $7.763 \pm 0.65$ & $3.746 \pm 0.37$ & $13.975 \pm 1.46$ & 0.000 & 0.000 & 0.000 \\
\hline $\begin{array}{c}\text { Duration of } \\
\text { analgesia(mins) }\end{array}$ & $435.75 \pm 34.61$ & $233.25 \pm 19.15$ & $1094.5 \pm 27.3$ & 0.000 & 0.000 & 0.000 \\
\hline Number of doses & $4.0 \pm 0.0$ & $6.7 \pm 0.7$ & $2.0 \pm 0.0$ & -- & -- & -- \\
\hline
\end{tabular}

Table 1 shows age wise distribution, weight wise distribution was similar in all the three groups. The onset of analgesia was short in Fentanyl group when compared with other two groups which was statistically highly significant $(\mathrm{p}=0.000)$. The onset of analgesia in Buprenorphine group was significantly longer than other two groups statistically $(\mathrm{p}=0.000)$. The duration of analgesia was longest in Buprenorphine group which was statistically significant compared to other groups $(p=0.000)$. The duration of analgesia was shortest in fentanyl group which was statistically significant compared to other groups $(\mathrm{p}=0.000)$. The number of doses were minimum in Buprenorphine group followed by Tramadol group, which has less requirement of doses than Fentanyl group.

Table 2 shows comparison of VAS Score among the three groups.

\begin{tabular}{|c|c|c|c|}
\hline & Group T(n=20) & Group F(n=20) & Group B(n=20) \\
\hline $0 \mathrm{hr}$ & 1.1 & 1 & 1 \\
\hline $1 \mathrm{hr}$ & 0 & 0 & 0 \\
\hline $2 \mathrm{hrs}$ & 0 & 0 & 0 \\
\hline $3 \mathrm{hrs}$ & 0 & 0.7 & 0 \\
\hline $4 \mathrm{hrs}$ & 0 & 0.3 & 0 \\
\hline $5 \mathrm{hrs}$ & 0 & 0 & 0 \\
\hline $6 \mathrm{hrs}$ & 0.36 & 0.3 & 0 \\
\hline $7 \mathrm{hrs}$ & 0.55 & 0.4 & 0 \\
\hline $8 \mathrm{hrs}$ & 0.1 & 0.25 & 0 \\
\hline $9 \mathrm{hrs}$ & 0 & 0.1 & 0 \\
\hline $10 \mathrm{hrs}$ & 0 & 0.36 & 0 \\
\hline $11 \mathrm{hrs}$ & 0 & 0.25 & 0 \\
\hline $12 \mathrm{hrs}$ & 0.25 & 0.4 & 1 \\
\hline $18 \mathrm{hrs}$ & 0.6 & 0.65 & 0 \\
\hline
\end{tabular}




\begin{tabular}{|c|c|c|c|}
\hline $24 \mathrm{hrs}$ & 0 & 0 & 0 \\
\hline Table 2 shows the mean VAS score was less than 1 in all the groups during the 24hrs after first dose of epidural
\end{tabular}
topup.

Figure-2:Comparison of mean pulse rate (mean \pm SD,Beats/min) between groups.

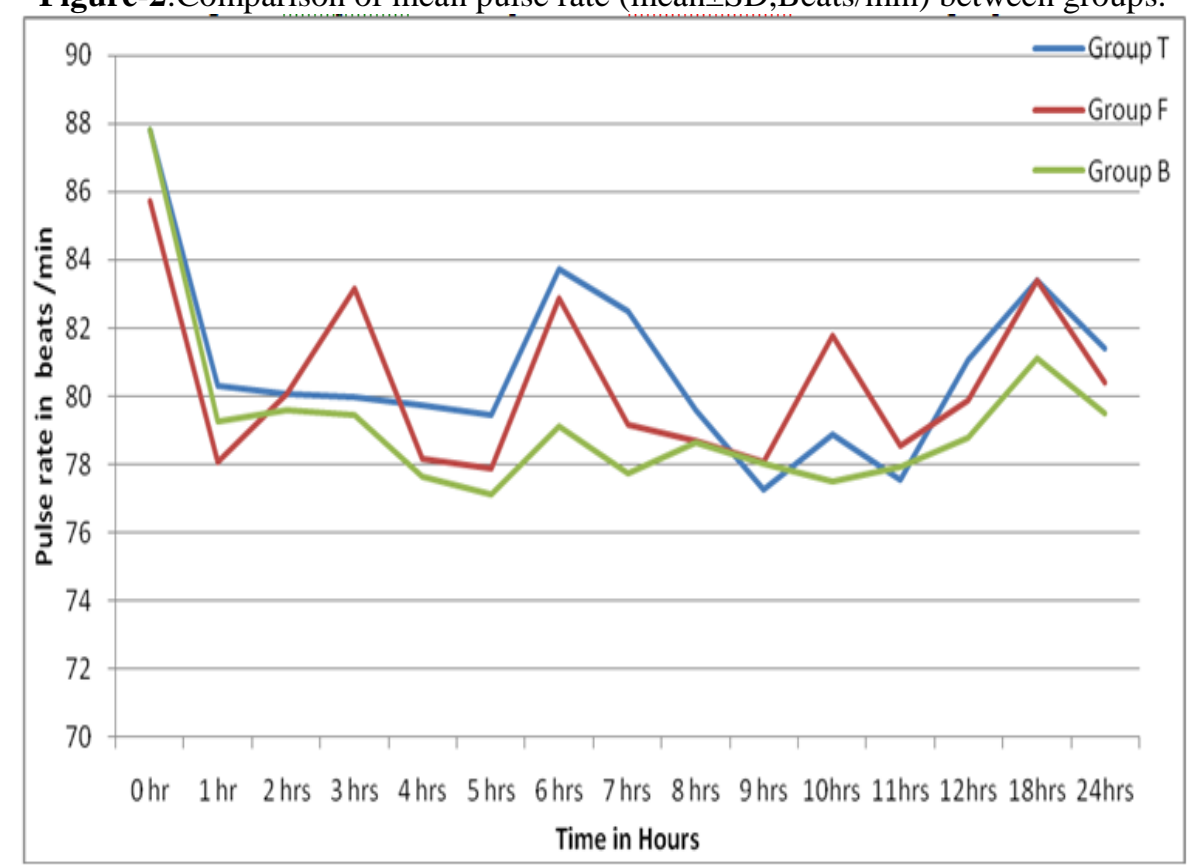

There was no significant difference in the mean pulse rate among the groups statistically $(\mathrm{p}>0.05)$.

Figure-3:Comparison of mean systolic blood pressure between the groups.

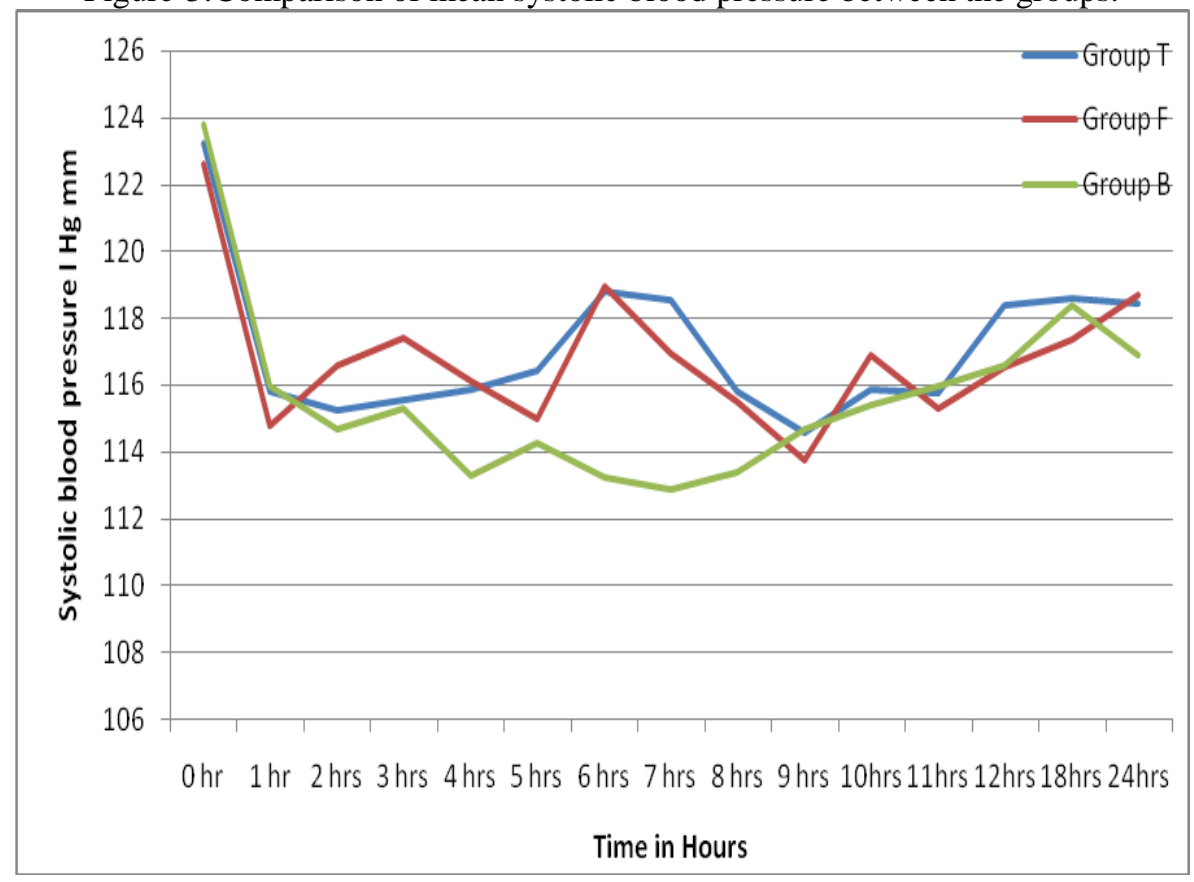

There was no significant difference in systolic blood pressure among the three groups at $0,1,2,3,4,5$, $8,9,10,11,12,18$ and $24 \mathrm{hrs}$ statistically $(\mathrm{p}>0.05$ ). There was an increase in systolic blood pressure in fentanyl group and Tramadol group compared to Buprenorphine group at $6 \mathrm{hrs}, 7 \mathrm{hrs}$ which was significant statistically $(\mathrm{p}<0.05)$. There was no significant difference in systolic blood pressure between Tramadol group and Fentanyl group statistically $(\mathrm{p}>0.05)$.

Figure-4:Comparison of mean diastolic blood pressure (mean $\pm \mathrm{SD}, \mathrm{mmHg}$ ) between the three groups. 


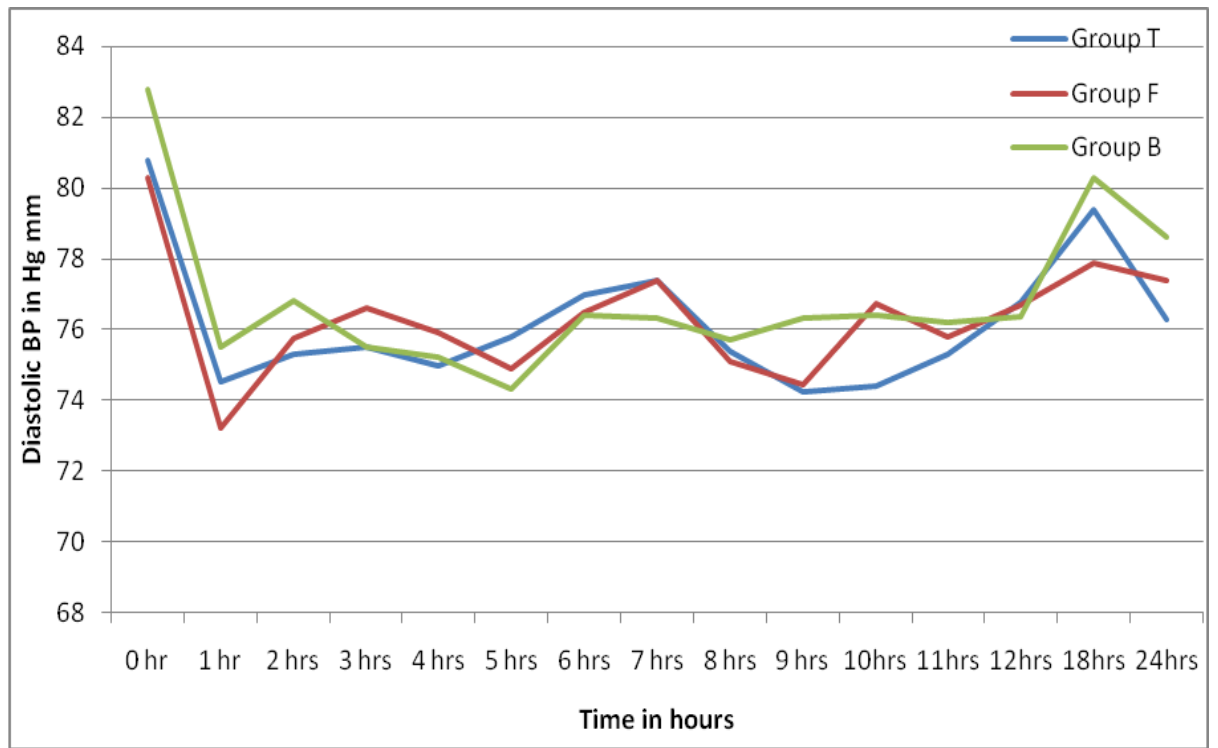

There was no significant difference in the mean diastolic blood pressure among the groups statistically (p > $0.05)$.

Figure-5: Comparison of mean respiratory rate (mean $\pm \mathrm{SD})$ between the groups.

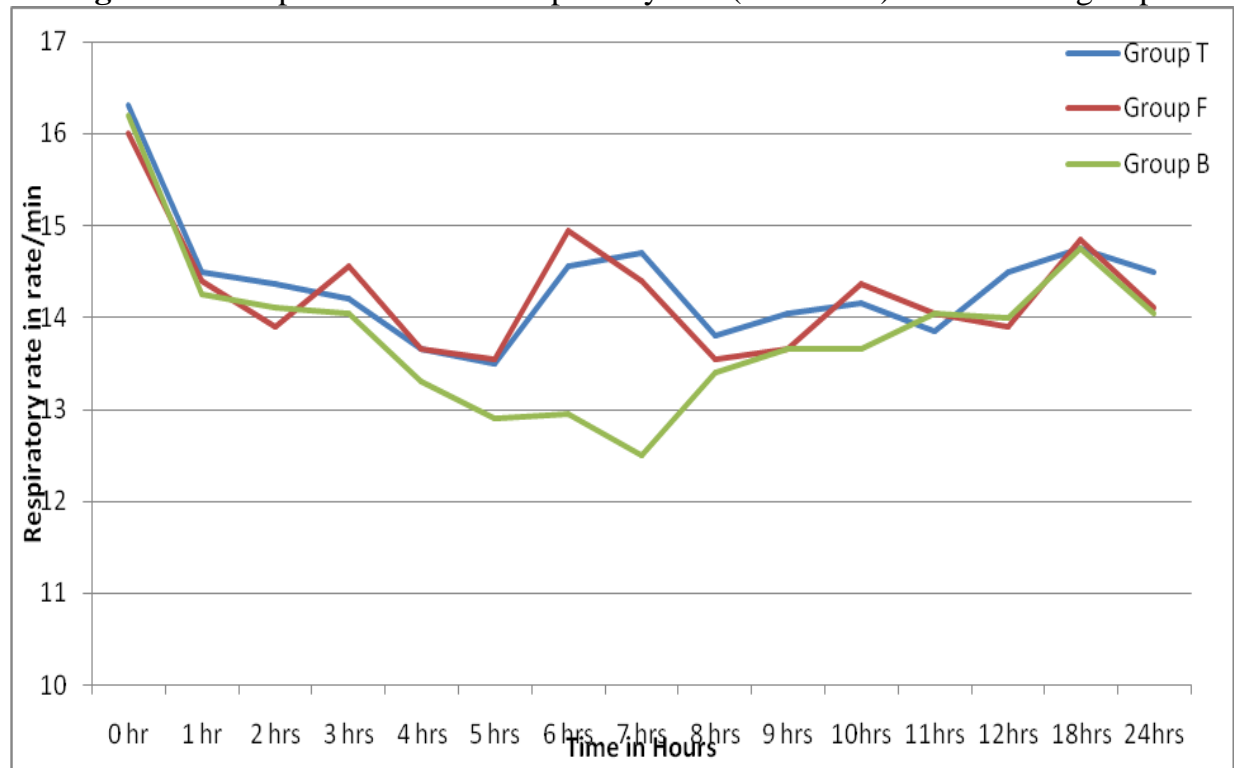

There was no significant difference in respiratory rate among the three groups at $0,1,2,3,4,5,8,9$, $10,11,12,18$ and 24 hrs statistically $(\mathrm{p}>0.05)$. There was an increase in respiratory rate in fentanyl group and Tramadol group compared to Buprenorphine group at $6 \mathrm{hrs}, 7 \mathrm{hrs}$ which was significant statistically $(\mathrm{p}<0.05)$. There was no significant difference in respiratory rate between Tramadol group and Fentanyl group statistically $(\mathrm{p}>0.05)$.

Table-2: Comparison of side effects between the groups.

\begin{tabular}{|c|c|c|c|}
\hline & GROUP T & GROUP F & GROUP B \\
\hline Nausea and Vomiting & 6 & 4 & 2 \\
\hline Hypotension & 0 & 0 & 0 \\
\hline Resp. depression & 0 & 0 & 0 \\
\hline Urinary retention & 1 & 0 & 4 \\
\hline Pruritis & 0 & 3 & 0 \\
\hline
\end{tabular}

In the present study, Nausea \& Vomiting was observed in 6 patients of Tramadol group, 4 patients of fentanyl group and 3 patients of buprenorphine group. Urinary retension was observed in one patient in Tramadol group and 4 patients of Buprenorphine group. No Patient in Fentanyl group had urinary retension in present study. Pruritis was observed in present study, only in 3 patients fentanyl group. No patient had pruritis in 
Tramadol \& Buprenorphine group. Hypotenison \& respiratory depression was not observed in any group of patients.

\section{Discussion}

Despite improvements in peri-operative care, major surgical operations are still followed by sequelae such as pain, organ dysfunction and prolonged convalescence.It has been assumed that sufficient pain relief will improve the surgical outcome with reduced morbidity, need for hospitalization and convalescence and there is common consensus that optimal pain relief is a prerequisite for early postoperative recovery ${ }^{10}$. Takekazu Terai, Hidekazu Yukioka et al (1993) had a study on post operative pain relief with lumbar epidural or intramuscular buprenorphine in 31 patients undergo hepatectomy. When patients first complained of pain after surgery, 0.06 $\mathrm{mg}$ or $0.12 \mathrm{mg}$ buprenorphine in $10 \mathrm{ml}$ or $20 \mathrm{ml}$ of saline was administered by epidural route or $0.12 \mathrm{mg}$ was administered intramuscularly. Epidural buprenorphine $0.06 \mathrm{mg}$ in $20 \mathrm{ml}$ saline and intramuscular buprenorphine $0.12 \mathrm{mg}$ each yielded only incomplete analgesia. Epidural buprenorphine $0.12 \mathrm{mg}$ in $10 \mathrm{ml}$ or $20 \mathrm{ml}$ of saline produced complete analgesia of duration about $10 \mathrm{hrs}$. There were no significant changes over time in respiratory and circulatory variables induced by buprenorphine. No patient had serious adverse effects. Lumbar epidural administration of buprenorphine $0.12 \mathrm{mg}$ diluted to 10 to $12 \mathrm{ml}$ with saline is recommended by them for induction of post operative analgesia following hepatectomy ${ }^{11}$. Choi PT, Bhandari M \& colleagues (2003) studied a clinical trail of patients undergoing hip or knee replacements, in which post operative lumbar epiduro analgesia was compared to other methods for pain relief. They concluded that for pain relief with movement after surgery, patients receiving epidural analgesia reported lower pain scores than patients receiving systemic analgesia. These benefits are more during early postoperative period ${ }^{12}$. Sawhney S, R.C.Gupta et al (2004) had done a prospective, randomized study to evaluate the quality of analgesia provided by Bupivacaine, Morphine \& Ketamine given in epidural space, in various combinations in 60 postoperative patients. They concluded that Ketamine and Morphine given as a combination in the epidural space provide an excellent postoperative analgesia. The quality and duration of analgesia provided by the combination is significantly better than those when these drugs were given alone.

There was also no change in the incidence and the pattern of complications. Hence they recommended the use of Ketamine $(0.5 \mathrm{mg} / \mathrm{kg})$ in combination with morphine $(0.05 \mathrm{mg} / \mathrm{kg})$ given epidurally for postoperative analgesia $^{13}$. S.A.Lytle, D.M.Gold Smith and colleagues (1991) had done a retrospective analysis of 134 patients who received continuous epidural Fentanyl for postoperative analgesia. Using a concentration of $5 \mu \mathrm{g} / \mathrm{ml}$ of Fentanyl, patients received continuous epidural infusions for 24 to 72 hours postoperatively. Side effects were less than, or comparable to, those of epidural morphine. No side effects occurred in $70.6 \%$ of the patients reviewed. These data show that epidural Fentanyl provides good to excellent pain relief with minimal side effects. Jeffray A. Grass, Neal T. Sakima and colleagues (1997) conducted a randomized double bind, dose response comparison of epidural Fentanyl versus Sufentanil analgesia after cesarean section. Eighty women undergoing cesarean section were randomly assigned to receive double blind epidural administration of Fentanyl $(25,50,100$ or $200 \mu \mathrm{g})$ or Sufentanil $(5,10,20$ or $31 \mu \mathrm{g})(\mathrm{n}=10$ per group) upon complaint of pain postoperatively. Visual analogue scales (VAS $0-100 \mathrm{~mm}$ ) were used to assess pain. They suggested that the relative analgesic potency of epidural S:F is approximately 5 and that there was no differences between the opioids in the onset, duration and effectiveness of analgesia when equianalgesic doses are administered postoperative after lidocaine anesthesia for cesarean section. G. Ozalp, F.Guner and colleagues (1998) had done a study to determine the efficacy and safety of patient - controlled epidural analgesia of morphine or fentanyl in combination with Bupivacaine for postoperative pain relief. They concluded that both methods were effective in prevention of pain but, because of fewer side effects, Fentanyl may be preferable to Morphine ${ }^{14}$. Michele Curatalo, Thomas W. Schnider \& colleagues (2000) applied an optimization model (direct search) to find the optimal combination of bupivacaine dose, fentanyl dose, clonidine dose and infusion rate for continuous post operative epidural analgesia. Twenty combinations were analyzed. The optimization procedure leads to the reduction in the incidence of side effects and in the mean pain scores. The three best combination of Bupivacaine dose $(\mathrm{mg} / \mathrm{L})$, Fentanyl dose $(\mu \mathrm{g} / \mathrm{L})$, clonidine dose $(\mu \mathrm{g} / \mathrm{L})$ and infusion rate $(\mathrm{ml} / \mathrm{L})$ were: $9-21-5-7$, 8-31-0-9, 13-25-0-9 respectively. They concluded that these three combinations may be the optimal ones to provide postoperative analgesia after major abdominal surgery ${ }^{15}$. Premila Malik, Chhavi Manchanda and Naveen Malhotra (2006) had conducted a prospective, randomized double blind study to assess and compare the safety and efficacy of post operative analgesia with epidural butorphanol and fentanyl. 60 patients were randomly divided into two groups $\mathrm{A}$ and $\mathrm{B}$ of 31 each receiving epidural butorphanol $2 \mathrm{mg}$ and epidural fentanyl $50 \mu \mathrm{g}$ respectively. Timing of incremental doses, interval between injections and total dose of analgesic drug given in $24 \mathrm{hrs}$ were recorded. They concluded that both butorphanol and fentanyl are effective and safe drugs for postoperative epidural analgesia with minor side effects ${ }^{16}$. Koshy.T, Afzal.L, Kaur.B (1994) had done a double blind study of comparison of epidural morphine and epidural buprenorphine for postoperative analgesia. They compared $4 \mathrm{mg}$ of epidural morphine with $0.12 \mathrm{mg}$ of epidural buprenorphine for postoperative 
analgesia. All the patients were observed for $48 \mathrm{hrs}$ postoperatively and assessed for onset, duration and potency of analgesia and side effects. Both the drugs exhibited good analgesic potency by significant reduction in pain score as assessed by Magill's classification. Onset of action was almost equal for both the drugs but buprenorphine showed a statistically significant longer duration of action. The incidence of side effects was also much less after buprenorphine. Thus, they inferred that buprenorphine has an edge over morphine on account of a longer duration of action with minimal side effects ${ }^{17}$. Yasuko Miwa, Eiji Yonemura et al (1996) studied that effect of epidural buprenorphine on minimum olveolar concentration (MAC) of volatile anaesthetics, duration of analgesia and respiratory function in the perioperative period. They concluded that epidural buprenorphine administration of $4 \mu \mathrm{g} / \mathrm{kg}$ provided prolonged analgesia when used as a pre-emptive analgesia and resulted in dose dependent reduction of anaesthesia during surgery and analgesics in post operative period ${ }^{18}$. D. Kumar, $\mathrm{N}$ Dev and N Gupta (1997) did a comparative study of epidural Buprenorphine and Ketamine for postoperative pain relief. They concluded that although both the drugs produced analgesia without any significant side effects, the analgesia produced by $31 \mathrm{mg}$ Ketamine is short lived and unpredictable where as Buprenorphine $0.15 \mathrm{mg}$ had produced relatively longer lasting analgesia of better quality.

Abdul Hakim, A.M.Hashia et al (2007) conducted a comparative study between epidural morphine and buprenorphine for postoperative analgesia. Hundred patients were equally divided into two groups to receive either $0.12 \mathrm{mg}$ buprenorphine (group 1) or $2 \mathrm{mg}$ morphine (group 2) epidural for pain relief. Patients were observed for 24 hours postoperatively for onset, duration and potency of analgesia with these drugs besides the side effects. Both the drugs showed significant pain relief. Onset of analgesia was equal for both the drugs but buprenorphine showed statistically significant longer duration of action than morphine. The incidence of side effects was less with buprenorphine compared to morphine. They concluded that epidural buprenorphine for post operative analgesia has longer duration of action and lower incidence of side effects than morphine. Pinky Rathie, R S Verma et al (1998) had shown in their study of postoperative pain relief by epidural tramadol that epidural tramadol can be used for adequate, safe and prolonged postoperative analgesia. Sahar Siddik-Sayyid, Marie Aouad-Maroun and colleagues (1999) compared the postoperative analgesic effect of 100mg Vs. $200 \mathrm{mg}$ epidural tramadol and saline in patients undergoing elective cesarean section. They found out that epidural tramadol 100mg can provide adequate postoperative analgesia without respiratory depression in patients after cesarean delivery ${ }^{19}$. Paul S Myles, Sally Troedel et al (1999) conducted study on the pain visual analogue scale whether it is linear or non linear. They studied 52 postoperative patients and measured their pain intensity using VAS. They have shown that, in postoperative patients with acute mild to moderate pain, the VAS score is a linear scale. Changes in the VAS score represent a relative change in the magnitude of pain ${ }^{20}$.

\section{Conclusion}

From the present study it can be concluded that, Quality of analgesia was equal with all the three drugs. Fentanyl has earliest onset of analgesia, but because of its shorter duration of analgesia it have to be given more frequently than tramadol and buprenorphine. Buprenorphine has larger duration of analgesia and hence required very less number of doses compared to tramadol and fentanyl. But onset of analgesia was longer with buprenorphine. Tramadol also produced similar quality of analgesia with onset of analgesia and duration of analgesia occurring between fentanyl and buprenorphine. Side effects observed were not worrisome. With advent of newer opioids with fewer side effects, the search for appropriate opioid for epidural administration to provide postoperative pain relief still continues. With the introduction of infusion pump in postoperative ward further research can be directed towards patient controlled analgesia and continuous epidural analgesia.

\section{References}

[1]. Desai P, Patel P, Gupta A (2006) Epidural analgesia in labor. J Obstet Gynaecol India 56: 417-422.

[2]. Shital H, Hardik B, Rachit M, Devanshi P (2013) A study of fetomaternal outcome of epidural analgesia during labor. National Journal of Medical Research.

[3]. Dahan A, Yassen A, Bijl H, et al. Comparison of the respiratory effects of intrave- nous buprenorphine and fentanyl in humans and rats. Br J Anaesth 2005;94(6):825-34.

[4]. Fang J, Hwang T, Huang Y, et al. Transdermal iontophoresis of sodium noniva- mide acetate. V. Combined effect of physical enhancement methods. Int J Pharm 2002;235(1-2):95-105.

[5]. Simpson K. Individual choice of opioids and formulations: strategies to achieve the optimum for the patient. Clin Rheumatol 2002;21(Suppl 1):S5-8.

[6]. Ballantyne J, LaForge K. Opioid dependence and addiction during opioid treat- ment of chronic pain. Pain 2007;129(3):235-55.

[7]. Mitra S, Sinatra R. Perioperative management of acute pain in the opioid dependent patient. Anesthesiology 2004;101(1):212-27.

[8]. Mehta V, Langford R. Acute pain management for opioid dependent patients. Anaesthesia 2006;61(3):269-76.

[9]. Witjes W, Crul B, Vollaard E, et al. Application of sublingual buprenorphine in combination with naproxen or paracetamol for post-operative pain relief in chole cystectomy patients in a double-blind study. Acta Anaesthesiol Scand $1992 ; 36(4): 323-7$

[10]. Fang J, Hwang T, Huang Y, et al. Transdermal iontophoresis of sodium noniva- mide acetate. V. Combined effect of physical enhancement methods. Int J Pharm 2002;235(1-2):95-105. 
[11]. Takekazu Terai, Hidekazu Yukioka, Osamu Morimoto, Mitsugu Fujimori. Lumbar epidural buprenorphine for postoperative pain relief following hepatectomy. Journal of Anaesthesia, December 1994, Volume 8, Issue 4, pp 410-414.

[12]. Choi PT, Bhandari M, Scott J, Douketis J. Epidural analgesia for pain relief following hip or knee replacement. Cochrane Database Syst Rev. 2003;(3):CD003071.

[13]. Gupta B, D'souza N, Sawhney C, Farooque K, Kumar A, Agrawal P et al. Analyzing fat embolism syndrome in trauma patients at AIIMS Apex Trauma Center, New Delhi, India. J Emerg Trauma Shock 2011;4:337-41.

[14]. Ozalp G, Guner F, Kuru N, Kadiogullari N. Post-operative patient controlled epidural analgesia with opioid bupivacaine mixtures. Can J Anesth 1998;45:938-42.

[15]. Michele Curatolo, Thomas W. Schnider, Steen Petersen-Felix, Susanne Weiss, Christoph Signer, Pasquale Scaramozzino, Alex M. Zbinden. A direct search procedure to optimize combinations of epidural bupivacaine, fentanyl, and clonidine for postoperative analgesia. ITHS.

[16]. Malik P, Manchanda C, Malhotra N. Comparative evaluation of epidural fentanyl and butorphanol for postoperative analgesia. J Anaesth Clin Pharmacol. 2006;22(4):377-82.

[17]. Koshy T, Afzal L and Kaur B. A comparison of epidural Morphine and epidural Buprenorphine for post operative Analgesia: A double blind study. Ind J Anaesth. 1994; 42: 305.

[18]. Yasuko Miwa, Eiji Yonemura, Kazuaki Fukushima. Epidural administered buprenorphine in the perioperative period. Canadian Journal of Anaesthesia. September 1996, 43:907.

[19]. Sahar Siddik-Sayyid MD FRC\& Marie Aouad-Maroun MD, Danielle Sleiman MD, Maria Sfeir MD, Anis Baraka MD FRCA. Epidural tramadol for postoperative pain after Cesarean section. CAN J ANESTH 1999, 46:8, pp 731-735.

[20]. Paul S. Myles, MBBS, MPH, MD, FFARCSI, FANZCA, Sally Troedel, MBBS, Michael Boquest, MBBS,and Mark Reeves, MBBS; The Pain Visual Analog Scale: Is It Linear or Nonlinear? Department of anaesthesia and pain management. Anaesth Analg, 1999, 89:1517-20. 